\title{
A escritura da memória: mostrar palavras e narrar imagens ${ }^{1}$ \\ Márcio Seligmann-Silva
}

\begin{abstract}
Definição do presente como catástrofe [...]: a catástrofe é o progresso, o progresso é a catástrofe

Walter Benjamin ${ }^{2}$
\end{abstract}

$\mathrm{Na}$ era da computação e da implantação do ciberespaço vivemos diariamente — nas situações mais banais - as conseqüências das inovações tecnológicas. Essas conseqüências são, na verdade, devastadoras se pensarmos na imagem do homem herdada da tradicional antropologia filosófica. Nosso corpo — submetido aos ditames dessa tecnologia — também é marcado por essas alterações e, com ele, a nossa visão do ser humano. Além de ficarmos usualmente horas a fio sentados diante da tela lisa e fria do monitor, penetramos através dessa "janela" em um mundo de informações de uma amplitude nunca sonhada pelo mais delirante enciclopedista. E mais: como evitar uma total reformulação na nossa concepção de homem se agora podemos finalmente construir o nosso Golem, os nossos Frankensteins ou os nossos robôs com inteligência artificial? Como traçar o limite entre o "natural" e o "artificial"? Se a nossa "humanidade" se torna mais frágil na medida em que é submetida a cada dia a um processo de redesenhamento das suas fronteiras (e da sua "essência”) não é de se estranhar que uma de nossas principais características, a de ser um "homo memor", ou seja, um "ser com memória", também seja repensada no contexto da era do ciberarquivo potencialmente infinito.

Existe uma vasta e interessante história da teoria da memória que vem sendo reatualizada nos últimos anos em função dessa revolução que atinge em cheio a noção de técnica e que não pode ser dissociada de certas características marcantes do século XX, enquanto uma era de extremos: se pela primeira vez em muitos séculos, pôde surgir mais de uma geração de homens que não foram à guerra e nunca pegaram em uma arma de fogo, por outro lado nunca se exterminou tantas vidas em uma escala tal e dentro de contextos nacionalistas e de "limpeza étnica" como nesse período. Além disso - e como conseqüência dessas catástrofes - o fim das ideologias e interpretações universais para o "caso humanidade" fez com que a articulação de nossa auto-imagem abandonasse qualquer esperança quanto a uma utopia "coletivista" e migrasse cada vez mais para os limites estreitos de nosso corpo. A teoria sociológica clássica foi substituída por uma reflexão sobre uma base antropológica, psicanalista e biológica. Mais do que nunca o universal passa pelo individual: não se trata mais apenas da "virada lingüística" no conhecimento, mas de uma crise muito mais profunda que corrói os seus fundamentos como um todo e o lança sobre um patamar onde a questão da memória é incontornável. 
No que segue irei primeiro recordar em linhas gerais o que foi a tradição da arte da memória, para em seguida tratar de alguns exemplos da arte contemporânea na sua relação com a memória e com essa antiqüíssima prática e teoria da arte da memória.

\section{Memória e reminiscência em Aristóteles}

A teoria da memória e da reminiscência de Aristóteles — que esteve na base das concepções de memória de toda Idade Média até à modernidade — pode ser reconstruida a partir de sua teoria do conhecimento exposta no tratado De anima. Na sua concepção dinâmica do nosso aparelho cognitivo, os cinco sentidos são responsáveis pela captação das sensações e seu transporte para a faculdade de imaginação que, por sua vez, fornece as imagens que constituem a matéria bruta da nossa faculdade intelectual. A parte da alma que cria imagens é considerada, em Aristóteles, como um a priori para o processo intelectual mais "elevado". Afinal de contas, para ele "a alma nunca pensa sem uma imagem mental" (De anima 432 a 17; cf. YATES 32) “... mesmo quando pensamos de modo especulativo, devemos ter uma imagem mental com a qual pensamos" (id. 432 a 9).

Aristóteles estruturou no plano tópico de sua teoria, os três sentidos internos (memória, imaginação e engenho/razão) como contraponto dos cinco sentidos externos, e os localizou em três câmaras no cérebro. Os sentidos internos, seriam as faculdades da alma que trabalham as informações que vem do exterior. Essa arquitetura cerebral manteve-se constante por séculos a fora. Na câmara posterior encontrar-se-ia a Imaginação que realiza a tradução dos dados dos sentidos em imagens, mas que também gera imagens independentes, como ocorre quando sonhamos. Na câmara mediana teríamos o common sense que compara os dados e gera juízos. Na última câmara localizar-se-ia a memória, que é vista como um reservatório. (A. ASSMANN 30)

Em seu pequeno tratado De memoria et reminiscentia Aristóteles nota, no entanto, que a memória devido ao seu caráter de arquivo de imagens pertence à mesma parte da alma que a imaginação (De memoria et reminiscentia 450 a 24): ela é um conjunto de imagens mentais das impressões sensuais mas com um adicional temporal; trata-se de um conjunto de imagens de coisas do passado (sendo que esse dado temporal que Aristóteles destacou nessas imagens só veio a ser realmente levado a sério na tradição com a obra de Santo Agostinho). Graças a essa relação da memória com as impressões sensíveis, ela não é exclusividade dos seres humanos (em contraste com a recordação ou reminiscência que lhes é exclusiva). Aristóteles compara a imagem mental gerada pela impressão sensual a um retrato pintado que permanece na memória: "pois - ele escreveu - o estímulo produzido imprime uma espécie de semelhança com o percebido, exatamente como nós selamos com sinetes dos anéis" (De memoria et reminiscentia 450 a 30 s.). Ele concebe, portanto, a formação da imagem mental como o movimento de impressão de uma imagem na cera por um anel que sela. Como na famosa descrição do Teeteto de Platão, para Aristóteles também cada pessoa possuiria uma determinada consistência dessa superfície mnemônica, que é aproximada da noção de bloco de cera, o que determina a sua capacidade de reter mais ou menos informações: 
em certas pessoas, Aristóteles escreve, devido à incapacidade ou idade, a memória não se dá mesmo sob um forte estímulo, como se o estímulo ou selo fosse aplicado à água que corre; enquanto em outras, devido ao desgaste, como em paredes antigas de prédios, ou à dureza da superfície de apoio, a impressão não penetra. Daí os muito novos e os muito velhos terem memória fraca; eles estão no estado de fluxo: o jovem devido ao seu crescimento, o idoso, devido à sua decadência. Pelo mesmo motivo, nem o muito veloz, nem o muito vagaroso parece ter boa memória, os primeiros são mais úmidos do que deveriam ser e os últimos mais duros; nos primeiros a imagem não permanece na alma, e nos últimos ela não deixa nenhuma impressão (id. 450b 1-10)

No Teeteto, como disse, Sócrates, já estabelecendo essa relação entre a escritura e a memória, falava de um

cunho de cera; numas pessoas, maior; noutras, menor; nalguns casos, de cera limpa; noutros com impurezas, ou mais dura ou mais úmida, conforme o tipo, senão mesmo de boa consistência, como é preciso que seja. [...] Diremos, pois, que se trata de uma dádiva de Mnemenosine, mãe das Musas, e que sempre que queremos lembrar-nos de algo visto ou ouvido, ou mesmo pensado, calcamos a cera mole sobre nossas sensações ou pensamentos e nela os gravamos em relevo, como se dá com os sinetes dos anéis. Do que fica impresso temos a lembrança e conhecimento enquanto persiste a imagem; o que se apaga ou não pôde ser impresso, esquecemos e ignoramos (191 c d; Cf. 194 c- 195 a).

Aristóteles distingue de modo claro entre memória e reminiscência, como o nome do seu texto o indica. A reminiscência é definida como a recuperação intencional de um conhecimento ou de uma sensação. Ela é marcada por dois princípios: o de associação e o de ordem. A associação pode se dar via similaridade, inversão ou por contigüidade. Por outro lado, a ordem da recordação pode seguir a ordem da apreensão dos objetos: é fácil de nos recordarmos do que segue uma ordem, como ocorre na matemática. Aristóteles menciona também a utilização de locais para recordar das coisas, ou ainda fala em possíveis séries, como na sucessão de letras a b c d e f g h, sendo que ele destaca que também são possíveis erros no processo de recordação assim ordenado:

\footnotetext{
se uma pessoa não encontrar o que busca em A, ele o fará em E; pois a partir desse ponto pode-se ir em qualquer direção, ou seja, tanto para D como para F. Se uma pessoa não quer uma dessas, ele recordar-se-á passando para F, se ele quiser G ou H. Caso contrário, ele passa para D. Sempre tem-se sucesso desse modo. O motivo pelo qual nós nos recordamos e algumas vezes não, apesar de iniciar do mesmo ponto, é que é possível prosseguir do mesmo ponto de partida para mais de um destino; por exemplo, de $\mathrm{C}$ podemos ir direto para F ou apenas até D. (De memoria et reminiscentia 452 a15ss.; cf. YATES 34s.)
}

Em Aristóteles, portanto, encontramos tanto uma concepção da memória como escritura na nossa placa mnemônica das impressões do mundo, como também uma forte concepção de reminiscência ou recordação, como um procedimento de leitura — e, como é evidente, a comparação com as letras do alfabeto não é de modo algum casual aqui. O elemento ativo da memória é comparado ao modo de ação de um pesquisador ou viajante que busca a inscrição mnemônica pelos labirintos de nossa memória-arquivo. A noção de associação também é essencial no nosso contexto: a estruturação da recordação - e por- 
tanto do discurso de um modo geral, que sempre está recuperando informações arquivadas - funciona a partir de um princípio de leitura de semelhanças que não deixa de lembrar a definição aristotélica, da sua Poética, do homem como um "ser mimético".

Como Yates recordou em sua obra clássica sobre The art of memory (de 1966), para a escolástica, Aristóteles com esse texto teria dado a sua aprovação para a mnemotécnica. É claro que isso está longe de ser evidente. A escolástica e a mnemotécnica pós-aristotélica identificaram nessa centralidade das imagens da teoria do conhecimento de Aristóteles um ponto em comum com as suas próprias doutrinas. Por outro lado, se a memória além do seu aspecto espacial e dinâmico, também é vista como um constructo onde imagens e conceitos se entrelaçam, então estamos de fato em um campo muito propício tanto para a arte da memória (ou, mais propriamente, para as técnicas de recordação e de fixação na memória), como também já está indicado que essa reflexão sobre a memória passa por uma crença na possibilidade de tradução recíproca entre palavras e imagens. Vejamos esse aspecto mais de perto na tradição antiga da arte da memória.

\section{A arte da memória}

A arte da memória tem como a sua figura originária (histórica e mítica) Simônides de Ceos (556-468 aC). Três anedotas que cercam a figura desse poeta mostram em que medida a arte da memória deve muito ao culto da memória no sentido do louvor aos grandes feitos (e aqui deveríamos pensar evidentemente no conceito de fama), ao culto dos mortos (lembremos da noção de piedade) e, finalmente e paradoxalmente, ao desejo de poder selecionar o que queremos nos lembrar e, portanto, também de poder determinar o que queremos nos esquecer. A primeira dessas anedotas é a mais conhecida e constitui um lugar comum em qualquer estudo sobre da arte da memória. Refiro-me evidentemente à história do banquete que foi oferecido em homenagem ao pugilista Skopas. Durante essa recepção, eu recordo rapidamente, Simônides - que fizera um encômio em sua homenagem no qual louvara também Castor e Pólux - foi chamado à porta por duas pessoas que queriam falar com ele. Ao chegar à soleira do salão, Simônides não encontrou ninguém; mas logo compreendeu a mensagem bem como quem a portara: o salão desabou matando a todos. Os dióscuros o recompensaram pelo encômio com a sua vida. O teto da sala de recepções caíra com uma violência tal sobre os convivas, que eles ficaram totalmente desfigurados e irreconhecíveis. Simônides, o único sobrevivente, pôde nomear cada um dos cadáveres graças à sua arte da memória. Na medida em que ele se recordava exatamente do local que cada conviva ocupara, todos puderam ser identificados. - A segunda anedota também trata de enterro e da sobrevivência do pai da mnemotécnica: durante uma de suas viagens ele teria encontrado um cadáver e imediatamente providenciado o seu enterro. $\mathrm{Na}$ noite seguinte a esse evento, o espírito do cadáver surgiu em um sonho de Simônides para lhe prevenir que o barco no qual ele deveria embarcar iria afundar. Simônides desistiu de continuar a sua viagem e a embarcação de fato naufragou, matando todos os seus passageiros. (A. ASSMANN 35 ss.) - Se nessa anedota, o passado/os mortos já assumem uma forma espectral (e o seu culto, uma maneira de apaziguá-los), na última historieta que eu gostaria de recordar aqui esse espectro assume a sua face assustadora e não mais salvacionista. 
Cícero narra que o general e político ateniense Temístocles (circa 524-459 aC), responsável pela derrota dos persas na Batalha de Salamina e, portanto, a quem Atenas devia o seu poderio sobre o Mediterrâneo, quando já estava idoso, devido a intrigas, foi submetido a um tribunal que o condenou ao ostracismo. Durante o seu exílio, em uma ocasião Simônides teria oferecido ensinar-lhe a sua arte da memória. Temístocles - que era conhecido por sua memória prodigiosa - recusou a oferta dizendo que ele necessitava de uma outra arte: a arte do esquecimento. O general sofria de "memória demais" e não carecia de uma ars memoriae. (WEINRICH 23 ss.). Apesar de sabermos que não pode existir rigorosamente falando uma ars oblivionis (ECO), não é menos verdade que a Antigüidade também nos legou muitos exemplos, belamente analisados por Harald Wenrich, de como o esquecimento pode ser atingido: Odisseus encantado por Circe e Calipso, a sua tripulação na ilha dos lotófagos, Ovídio tratando do Amor Lethaeus etc. Nessa terceira anedota aparece a imagem de um passado que não é mero conjunto de fatos que podem ser guardados, mas que constituem ao mesmo tempo uma peça fundamental na nossa vida e na nossa identidade. Com relação a esse passado fica mais evidente em que medida a memória não é apenas um "bem", mas também encerra ainda uma carga espectral que gostaríamos muitas vezes de esquecer - ou enterrar, como fazemos com nossos mortos. Esse passado que não quer passar também é um íntimo conhecido nosso, moradores da era dos extremos.

A arte da memória foi descrita na Antigüidade por vários retores, sendo que as descrições que chegaram até nós são as de Cícero, Quintiliano e sobretudo a do autor do tratado Ad Herennium. ${ }^{3}$ Cícero vê a memória como uma das cinco partes da retórica (inventio, dispositio, elocutio, memoria, pronunciatio) (Cf. De inventione; YATES 8s.). A arte da memória servia tanto como uma técnica para decorar longos discursos como também deveria desenvolver a capacidade de memorização do orador (essencial, por exemplo, na cena do tribunal, quando todos argumentos do oponente deveriam ser cuidadosamente registrados). $\mathrm{Na}$ Antigüidade não só não existia a impressão de livros, como tampouco havia papel tal como nós o conhecemos hoje; daí a importância da memória para o orador. Também em Cícero é patente o valor atribuído à visão dentro da técnica de memorização. O princípio central da mnemotécnica antiga consiste na memorização dos fatos através da sua redução a certas imagens que deveriam permitir a posterior tradução em palavras: a realidade (res) e o discurso final (verba) deveriam ser mediatizado pelas imagens (os imagines agentes). Essas imagens por sua vez, deveriam ser estocadas na memória em certos locais (loci) imaginários ou inspirados em arquiteturas de prédios reais. O importante era que o retor tivesse domínio sobre esses espaços da memória que deveriam ser percorridos no ato de sua fala, quando cada imagem seria retraduzida em uma palavra ou em uma idéia. ${ }^{4}$ No texto $A d$ Herennium após o autor anônimo recordar topicamente que toda arte (tecne) é um complemento de um dom natural - no caso: o dom da memória - lemos:

[a memória artificial] baseia-se nos locais e nas imagens. Nós denominamos locais (loci) as realizações da natureza ou feitas pelos homens que ocupam um espaço limitado, constituem um todo, distinguem-se dos demais, de tal modo que a memória natural pode facilmente compreender e abarcar: por exemplo uma casa, um corredor com colunas, um canto, um arco e outras coisas similares. As imagens são formas, símbolos (notae), retratos (simulacra) daquilo que nós queremos recordar (meminisse): por exemplo, se quisermos nos recordar de 
um cavalo, de um leão, de uma águia, devemos depositar as suas imagens em determinados locais. (III, XVI, 29)

A explicação subseqüente do mecanismo da mnemotécnica é importante no nosso contexto, pois ela retoma a comparação com a escritura que nós já encontramos na teoria da memória e da reminiscência de Aristóles.

Assim como pessoas alfabetizadas anotam algo que é ditado e podem novamente ler aquilo que elas escreveram, do mesmo modo, aqueles iniciados na mnemotécnica podem depositar aquilo que eles ouviram em locais e graças a eles falar de memória. Pois os locais são totalmente comparáveis a uma tabuleta de cera ou a um papiro, as imagens às letras, a disposição ordenada das imagens, à escritura, e a fala do discurso, à leitura. (III, XVI, 30)

Esses locais e a sua sucessão devem ser de tal modo incorporados na nossa mente, que se tornem tão fixos quanto um suporte de escrita que pode sempre receber novas letras que substituem as anteriores por nós apagadas. Eles devem ser bem demarcados uns dos outros, ter uma dimensão mediana, ser iluminados de modo correto. No que tange à escolha das imagens, ela deve proceder seguindo o princípio da semelhança (que caracteriza a recordação) tanto com as coisas a serem lembradas (um princípio icônico quanto à imagem), como também com as palavras (iconicidade mediatizada pela semelhança sonora dos nomes) (III, XVI, 33). Vale a pena lermos o exemplo dado pelo autor do tratado $A d$ Herennium que "estranhamente" volta a tematizar morte e assassinato e a cena jurídica para tratar de memória:

Com freqüência nós damos conta de um conjunto de coisas apenas com um símbolo (nota) e com uma única imagem. Por exemplo, a acusação afirmou que o réu matou um homem utilizando veneno, que ele fez isso para se apropriar de uma herança e que existem várias testemunhas e pessoas cientes disso. Se para facilitar a defesa nós quisermos nos recordar desse primeiro ponto, devemos depositar no nosso primeiro local uma imagem com todos os fatos: nós imaginaremos a vítima em questão doente, estendida sobre uma cama (isso se nós a conhecermos, caso contrário teremos de tomar uma outra pessoa, que não deve ser alguém de baixo calão, de tal modo que ela rapidamente venha à nossa memória); ao lado de sua cama nós colocaremos o réu segurando uma taça com a mão direita e com um texto na esquerda de cujo dedo anelar devem pender testículos de carneiro. Desse modo nós poderemos nos recordar das testemunhas, da herança e do envenenamento da vítima. A seguir nós arranjaremos do mesmo modo os outros pontos da acusação em locais sucessivos, segundo a sua ordem, e quando a qualquer momento nós quisermos nos recordar de um ponto, se as imagens estiverem cuidadosamente dispostas e as caracterizarmos bem, poderemos facilmente recordar daquilo que queremos. (III, XVI, 33 s.)

O autor ainda caracteriza longamente os tipos de imagem que devemos escolher: seguindo uma lei que aprendemos com a natureza, devemos optar por imagens chocantes, que fogem à norma. Ele afirma, por exemplo, que nos recordamos de um eclipse do sol, mas o percurso cotidiano do sol não é excepcional e não deixa marcas na nossa memória. Coisas extremamente feias ou belas nos marcam, ele afirma destacando que faremos essas imagens que podem ficar muito tempo na memória "se nós as embelezarmos, por exemplo, com coroas ou com hábitos cor púrpura [...]; se nós enfeiarmos um objeto que nós 
apresentaremos, por exemplo, molhado de sangue ou de lama ou manchado com tinta vermelha, para que a sua forma se torne mais marcante [...]” (III, XVI, 37).

Não caberia aqui recordar os caminhos percorridos pela arte da memória na Idade Média, cujas marcas podem ser lidas tanto na topografia desenhada por Dante na sua Divina Comédia, como também nas catedrais com a sua arquitetura simbólica, seus nichos repletos de imagens ("sangrentas", chocantes!) da paixão de Cristo, mas também com suas inúmeras representações pictóricas da hierarquia celeste ou das virtudes cardinais, na poesia imagética e na prática dos acrósticos etc. A função didática e reprodutora de idéias e da visão de mundo eclesiástica das obras medievais representa um campo de estudos em si; por outro lado a hibridização das palavras com imagens também respondia a um princípio básico da arte (leia-se: técnica) da memória. Com Frances Yates, podemos recordar ainda que mesmo a atração medieval pelo grotesco tem em parte suas raízes nessa doutrina da arte da memória (YATES 104). No Renascimento essa tradição tem continuidade tanto em tratados de pura mnemotécnica, como também em simples listas de imagines agentes e no desenvolvimento de alfabetos visuais (id. 113). Um dos sonhos dos tratadistas da memória dessa época - representado de modo exemplar pelo teatro da memória de Giullio Camillo - era justamente conseguir reduzir todo o conhecimento macrocósmico em um conjunto de imagens (um microcosmo) que poderia ser assimilado por uma só pessoa, de tal modo que com um simples olhar sobre as imagens organizadas de um modo panóptico, poderíamos nos apropriar de todo esse saber. A verdade enquanto a-lethéia (termo grego para verdade que significa literalmente: não-esquecimento) tal como ela era pensada na tradição platônica, aliara-se de um modo anti-clássico à doutrina da arte da memória. Por outro lado, a atração renascentista pelo hieróglifo somada à releitura dessa tradição neoplatônica por um filtro cabalista transformaram, finalmente, a arte da memória em uma espécie de subgênero da escrita de mistérios e de enigmas típica da "era das semelhanças", para falarmos com Foucault.

Mas essa história fascinante não pode ser desdobrada aqui. Com o livro impresso a arte da memória decaiu, ao menos na sua forma tradicional. Como afirma Frances Yates, as catedrais da memória foram destruídas pelo livro impresso (124).

Para nossa reflexão vários pontos dessa tradição da arte da memória clássica e da sua recepção são importantes: a doutrina dos loci que afirma uma concepção eminentemente visual/espacial da memória e que é aproximada da noção de escritura (tanto do ato de escrever como de sua leitura), a relação entre teoria da memória e o culto dos mortos, a ligação entre o sobreviver e a arte da memória, entre esta e a cena (retórica) do tribunal, bem como a doutrina das imagens marcantes (extraordinárias). No item culto dos mortos deveríamos ainda recordar que a manutenção do nome dos mortos - muitas vezes sob a forma de sua inscrição em epitáfios e lápides - constitui o núcleo antropológico da memória enquanto vis, ou seja, como força vital e construtora da identidade que é oposta à memória como ars (procedimento mecânico de arquivamento e recuperação de informações). (A.ASSMANN 33 ss.) É evidente que apenas a memória como ars que pode ser de certo modo substituída ou complementada pela máquina. Como afirmou Paul Ricoeur no seu livro La mémoire, l'bistoire, l'oubli (80): "para a memória artificial [ou seja, para a visão da memória como ars] tudo é ação, nada é paixão". Por outro lado, tampouco podemos desprezar a intima relação dessas duas modalidades de memória. Lembrando-nos do conceito 
de memória como fama, fica claro que o arquivamento de determinados nomes em detrimento de outros - e a memória sempre seleciona - já implica uma política da memória enquanto vis. À "má-memória” de Temístocles corresponde não só o seu desejo de apagála, mas também a possibilidade de uma reparação, de uma anistia: nem tanto um "esquecimento decretado", mas sim um "perdão recíproco" que poderia reconciliar Atenas com seu ilustre filho.

Já a noção escritural da memória e a doutrina dos loci põe em relevo a afirmação aristotélica que vimos acima, segundo a qual a memória se localiza na imaginação. Se com a imaginação ela compartilha esse caráter imagético ela mesma constitui, graças a esse aspecto, um "espaço" nas nossas mentes onde plantamos nossas paisagens mnemonicas e escrevemos com os imagines agentes. É essa localização entre o mundo sensível e o conceitual que caracteriza a imaginação que permite também o funcionamento da arte da memória enquanto dispositivo tradutório que ora traduz histórias em imagens, ora retrotraduz estas em novas falas ou textos. A arte da memória tem como um de seus movimentos básicos a transformação da história em uma escrita imagética e a sua legibilidade posterior. Se Plutarco atribuía a Simônides de Ceos a frase "a pintura é uma poesia silenciosa e a poesia uma pintura que fala”, então fica fácil compreender a cumplicidade entre essa tradição da arte da memória e a doutrina antiga da ut pictura poesis - ou seja, da crença na conversibilidade entre imagens e palavras, poesia e quadros. Como veremos, na arte da memória contemporânea, ainda que apareça de modo bem diverso, também esse elemento é central.

\section{A arte da memória no século XX}

Se é legítimo afirmar que a tradição retórica sofreu um processo de declínio a partir de meados do século XVIII e com o romantismo essa tradição foi dissolvida e o que dela restou foi incorporado a diversas disciplinas que se cristalizaram nas instituições acadêmicas no século XIX - como as filologias nacionais, as faculdades de direito e mesmo em algumas práticas literárias mais conservadoras - por outro lado não é menos verdade que a arte da memória enquanto parte dessa tradição foi sufocada pela onipresença do discurso historicista que implicou uma mudança radical de relacionamento com o passado. A Segunda consideração Intempestiva de Nietzsche, de 1872, representa a mais acabada resposta a esse domínio da visão histórica: aqui a história monumental e a tradicionalista - a que venera o passado e a que quer tudo conservar - são objeto de uma análise crítica que culmina em uma reflexão anti-historicista baseada na defesa do esquecimento feliz que deve liberar o homem para a ação.

No século XX o chão já estava preparado para uma volta do discurso sobre e da memória - sob condições evidentemente bem diversas das que determinaram esse discurso até o século XVIII. Se na filosofia Nietzsche plantara o grão do pensamento antihistoricista, na literatura a "crise do verso" diagnosticada por Mallarmé em 1895 na sua palestra ministrada na Universidade de Oxford e cujas conseqüências estão inscritas na poesia imagética do seu "Coup de dès" - também anunciou um corte com a tradição do realismo do romance do século XIX. Baudelaire, como é sabido desde um conhecido ensaio de Benjamin de 1939, foi o poeta lírico que soube incorporar o choque caracterís- 
tico da Modernidade na sua poética, com Mallarmé a literatura explodiu em uma nova constelação espaço-temporal que se desdobra agora nas novas criações poéticas digitais. Nas artes plásticas as vanguardas em poucos anos no início do século XX deram conta de revolucionar a noção de obra de arte: cubismo, futurismo e surrealismo instauraram regras tão novas para o jogo artístico, que pode-se dizer que as mudanças acumuladas em uma década foram mais amplas que as ocorridas nos duzentos anos, ou mais, anteriores.

Em linhas gerais esses são os pressupostos da arte da memória contemporânea: sem esquecermos o fundo histórico que marca todas essas mudanças e cujo paroxismo deu-se na Segunda Guerra Mundial. É a partir desse evento que o discurso da memória antes pensado no debate intelectual por autores como Bergson, Aby Warburg, Walter Benjamin e Maurice Halbwachs e praticado na escritura de Proust - vai moldar a produção de um importante filão das artes: a tal ponto que nas últimas décadas há quase que uma onipresença dos discursos da memória na cena artística internacional. Essa tendência foi agudizada pelos movimentos anti-colonialistas, pela emancipação das mulheres e das minorias. A necessidade de recosturar as identidades antes oprimidas e impedidas de se manifestar, ao lado do próprio movimento de luto pela perda de vidas gerada pela Grande Guerra, pelos movimentos de auto-afirmação das minorias e pelas lutas contra governos totalitários e autoritários, gerou uma cultura da memória que aqui neste espaço eu só poderei mostrar de modo limitado, restringindo-me às artes plásticas e, dentro dela, a alguns de seus representantes. Não podemos esquecer que essa cultura da memória nasce da resistência ao esquecimento "oficial" e a uma cultura da amnésia, do apagamento do passado, que caracteriza nossa sociedade globalizada pós-industrial.

Jochen Gerzé sem dúvida um dos artistas mais interessantes na atualidade quando se trata de pensar sobre a nossa cultura da memória. Sua arte lida há anos com a história recente da Europa, sendo que pelo fato dele ser um alemão, nascido em Berlim em 1940, a centralidade do passado nazista na sua temática não deve causar surpresa. Outra característica que faz desse artista um exemplo particularmente representativo da cena artística atual é a sua relação com a literatura e com a filosofia. Gerz não apenas estudou essas matérias, mas incorpora no seu trabalho textos e muitas vezes o próprio gesto da escritura. Ele escreve com textos e imagens. ${ }^{5}$ Estas muitas vezes são imagens fotográficas e o dispositivo fotográfico também é central na arte da memória na medida em que a fotografia é pensada, como o próprio Gerz afirma, como uma escritura visual (MESNARD 80); um conjunto de traços deixados pela luminosidade do "real", cuja apresentação - e não representação — está norteando a obra desse autor. ${ }^{6}$ A sua arte se desdobra normalmente no contexto de projetos que envolvem discussões com seus estudantes e com a comunidade, pesquisas, coleta de informações, de tal modo que muitas vezes a obra "em si", o resultado final, é o menos importante. Gerz é um crítico não apenas da temporalidade aparentemente eterna das obras de arte tradicionais - auráticas - e do elemento consolador que a identificação com essa pseudo-imortalidade traz, mas também é um opositor da instituição museológica tradicional. Uma de suas obras, "Exit/ Materialien zum DachauProjekt" ("Exit/ Materiais para o Projeto Dachau", 1972) é baseada nas fotos que ele fez em museus: fotos não de obras de arte, mas de placas como "Exit", "silêncio", "proibido fumar" etc. Gerz se revolta contra a instituição museológica que faz com que respondamos de modo mecânico ao ritual do culto das obras: nas suas palavras, no museu somos 
"vítimas do passado". (GERZ 34) No sentido oposto da musealização enquanto embalsamento do passado, Gerz pratica uma arte que quer encenar os processos de embalsamento desse passado: ele visa reatualizar esses processos de recalque e enterramento do passado - encriptamento, diríamos com o psicanalista Nicolas Abraham - particularmente dos eventos que não podem ser deitados na falsa continuidade do histórico. Daí a necessidade de se romper (seguindo as vanguardas "clássicas") com as paredes do museu tradicional, historicista, e partir para o domínio do espaço público. Daí também o desaparecimento e a invisibilidade estarem no centro da sua poética: ao invés do paradigma romântico do Pigmalião, ou seja, do artista como alguém que deveria dar vida à sua obra, Gerz ao encenar o desaparecimento não apenas está reafirmando a arte como algo além de toda ilusão, mas fazendo uma arte eminentemente política.

A política da memória no sentido mais nobre dessa expressão, pode ser lida, por exemplo no seu famoso anti-monumento contra o fascismo, feito junto com sua esposa, Esther Shalev-Gerz em Harburg. Esse monumento consistiu em um "obelisco" de 12 metros de altura, quadrado, com um metro de cada lado, recoberto de chumbo. Cinzéis estavam presos à obra e os espectadores eram convidados a escrever seus nomes sobre ela, numa forma de coletivização do trabalho do artista e de comprometimento com o tema. Quando a superfície estava totalmente cheia de inscrições, o monumento era enterrado dois metros e uma nova superfície lisa ficava acessível para as assinaturas. Por fim, em 1993 os últimos dois metros foram enterrados e o anti-monumento sumiu. Hoje ele existe como uma coluna enterrada na terra: as assinaturas, palavras anti-fascistas, mas também nazistas — até tiros o "monumento" recebeu — tudo encontra-se enterrado. Como nossos passados sempre estão ausentes, de certa forma enterrados na nossa memória. Mas até hoje perdura a discussão sobre o "monumento" que funciona como um potente catalisador de reflexões sobre os dispositivos mnemônicos. A superfície do chumbo é particularmente interessante no nosso contexto: não apenas porque chumbo é o metal saturnino, e Saturno é o planeta que rege os melancólicos, em termos freudianos, os que incorporaram um passado que não pode ser enlutado (FREUD 1975, vol. III), mas também porque ele encena a própria memória enquanto tablete de cera. Gerz ficou fascinado com o fato de que não podemos apagar as inscrições no chumbo. Podemos apenas rasurá-las ou escrever por cima. Não existe a possibilidade do apagamento inocente, anônimo. Ele funciona como uma espécie de bloco mágico (freudiano; FREUD 1975, vol.III) defeituoso, sem o dispositivo de apagamento das marcas na superfície e onde as camadas do palimpsesto acabam por anular toda possibilidade de inscrição e leitura ao menos no sentido tradicional dessas atividades, ou seja, dentro na nossa visão alfabética de escritura como uma sucessão lógica de fonemas e lexemas. A escritura torna-se puro traçamento e espaçamento: como as inscrições no nosso próprio inconsciente. Também esse elemento meta ou pré-semântico da escritura nesse "obelisco" não deixa de mimetizar a nossa (im)possibilidade de dar um sentido para o passado fascista. Essa mímesis, no entanto, não se reduz na obra de Gerz a um movimento reflexo: antes ao encenar o movimento de encriptamento do passado ele permite uma reflexão sobre ele. Ao invés de uma figurabilidade que tornaria o passado legível - como ocorre, por exemplo, em algumas obras de ficção sobre a Shoah (SELIGMANN-SILVA 2000) — Gerz apela para uma super literalidade que violenta nossos hábitos e nossa inércia que nos leva a não olhar para nossos passados encapsulados, 
assim como não olhamos para os enormes monumentos do século XIX nos centros de nossas cidades, os quais Freud, com razão, comparou aos sintomas de um histérico. ${ }^{7}$ De resto, Gertz chamou sua obra contra o fascismo de Mahnmal e não de Denkmal: enquanto para ele este último estaria ligado a uma comemoração de um passado positivo, o Mahnmal volta-se para um passado pesado, negativo (GERZ 147 s.) — assim como suas obras - e a arte da memória contemporânea — são negativos da nossa cultura da amnésia e constituem jogos onde é possível de virar ao avesso o Unheimlich (o estranho/sinistro) revelando seu outro lado, a outra face da sua moeda, o familiar (nosso passado) que está dentro de nós e nos é estranho. ${ }^{8}$ Uma outra obra de Gerz que pode ser posta ao lado desse antimonumento é o seu trabalho intitulado "2146 Steine, Mahnmal gegen Rassismus" ("2146 Pedras, Memorial contra o racismo") de 1993, que ele realizou em Saarbrücken. Essa obra foi o resultado de um trabalho com os alunos da escola de artes dessa cidade e se iniciou de um modo inusitado, como uma atividade noturna, na qual ele e seus alunos retiravam as pedras de pavimentação ao lado do castelo onde se encontra atualmente o parlamento estadual. As pedras eram substituídas na calada da noite por outras pedras similares. Após a inscrição do nome de um dos 2146 cemitérios judaicos da Alemanha sob a pedra, ela era devolvida ao seu lugar. Um dos pontos curiosos nesse projeto é que ele envolveu o levantamento - inédito — de todos os cemitérios judaicos da Alemanha realizado com a consulta a todas as organizações judaicas locais do país. Além, é claro, da própria idéia de realizar uma obra que novamente "des-obra" nosso processo de enterramento do passado. $\mathrm{O}$ anti-monumento existe apenas devido às discussões que existiram e persistem em torno dele - como nosso passado "desaparecido". Como Gerz afirmou em uma entrevista: "A memória não pode ter nenhum lugar fora de nós. O trabalho trata apenas disso." (GERZ 157) Ele recorda ainda ao falar dessa obra, que Steinpflaster, pedras de pavimentação, tem um duplo sentido em alemão: Pflaster significa tanto pedra, como também curativo, Wundpflarter, curativo de uma ferida: de trauma, poderíamos falar, recordando a etimologia grega do termo trauma. A obra reabre a cicatriz do passado, mas também a possibilidade de sua aproximação e libertação da cripta que condenava o passado a morar na área enfeitiçada e proibida do tabu e, desse local, comandava nossas reações mecânicas, nosso Agieren (acting-out), que estava no lugar da recordação.

No nosso contexto, poderíamos recordar ainda duas outras obras de Gerz: o seu "Questionário de Bremen 1995" e o "Monument vivant" de Biron, de 1996. Em ambas obras novamente interveio o questionário: em Bremen, Gerz propôs a seus 50.000 habitantes três perguntas: "O que para você é tão importante a ponto de você querer ver realizado no espaço público?", "Você acha que com os meios da arte contemporânea isso pode ser realizado?" e: "Você gostaria de estar pessoalmente implicado na realização desse trabalho?” (MESNARD 84). O resultado desse questionário e da discussão que se seguiu a ele não foi a construção de nenhuma das desejadas obras: Gerz inscreveu o nome de todos os autores da obra — a saber: da discussão — em uma placa que foi posta em um "canto" que ele implantou em uma ponte de Bremen. Olhando essa "obra" cada um poderia se recordar de seu projeto... Em Biron, uma pequena cidade francesa marcada pelas duas guerras mundiais, Gerz recebeu a encomenda de fazer uma obra para substituir o antigo obelisco aos mortos da cidade que estava quebrado. Ao invés de substituí-lo, o artista novamente realizou um questionário envolvendo toda população: nele ele pergun- 
tou o que seria para os habitantes de Biron tão importante a ponto de valer pôr em risco as suas próprias vidas. As respostas foram posteriormente gravadas — de modo fragmentário e anônimo, cerca de sete linhas de cada resposta - em plaquetas que foram fixadas no obelisco e no seu pedestal. A idéia é que esse "monumento" continue em perpétuo devir. Gerz não apenas integrou o monumento antigo na cidade, mas o próprio processo de recordação. "Nós apenas nos recordamos daquilo que nós nos esquecemos" (GERZ, 1996, 9), afirma o artista. Nas suas obras essa arte da memória dá continuidade à antiga arte da memória, ao entrelaçar culto dos mortos, escritura verbal e visual e o procedimento de fazer "listas" de nomes. "No final das contas tudo que fica são listas, listings" (GERZ 154), disse ele também. ${ }^{9}$

Eu gostaria ainda de tratar da arte da memória de outros artistas contemporâneos como Naomi Tereza Salmon, Christian Boltanski, Cindy Sherman, Horst Hoheisel, Andreas Knitz, Nuno Ramos, Marcelo Brodsky, Micha Ullman, Anselm Kiefer e Daniel Libeskind. Cada um deles desenvolveu uma poética própria onde a memória desempenha um papel de pólo aglutinador e as artes fazem jus ao fato de serem filhas de Mnemosine. Nas obras desses autores - que não posso tratar aqui por uma questão de tempo — algumas das principais características da arte da memória contemporânea vem à tona. Encontramos o procedimento de literalização do passado e do seu processo de transformação em cripta/ arquivo/ palimpsesto/ camadas "geológicas" (cf. "Asservate Exhibits" de Salmon e a obra de Hoheisel e A. Knitz "Zermahlene Geschichte" em Weimar [ainda em andamento], o Aschrottbrunnen [1987] e o "Denk-Stein-Sammlung" [1988-1995] de Hoheisel em Kassel e as obras de Kiefer com chumbo e palha), o uso da fotografia como meio de expressão (em Gerz, Salmon, Boltanski, Sherman, Ramos, Brodsky ${ }^{10}$ ), uma poética muito mais próxima da tradição do sublime e do abjeto que do belo (sobretudo em Sherman que também emprega o procedimento de tornar suas imagens chocantes e dá atributos aos seus personagens, como na pintura tradicional herdeira da arte da memória antiga ${ }^{11}$ ), o uso de palavras e de colagens (como na obra de N. Ramos "111", no "The Missing House" de Boltanski [1989] e nos trabalhos Kiefer que dialogam com a poesia de Paul Celan).

\section{Literalização imagética}

Gostaria de fechar essa reflexão falando de um trabalho de Nuno Ramos. Em 2 de outubro de 1992 a Polícia Militar invadiu a Casa e Detenção de São Paulo e o saldo macabro desse ato foi a morte de 111 presidiários. Nuno Ramos expôs a primeira versão da sua obra sobre esse massacre em novembro de 1992, portanto apenas um mês após o evento. Uma segunda versão foi exposta em 1993, no Gabinete de Arte Raquel Arnaud. Vale a penas citar a descrição que o próprio autor fez dessa obra, onde reencontramos muitos procedimentos da arte da memória não apenas enquanto mnemotécnica, mas também como culto dos mortos (como percebemos no acumulo de pedras nessa obra, que foi desde sempre uma constante na arte da memória), e ainda como documentação do passado, arquivamento, encriptamento, espaçamento (ou seja: re-encenação espacial da morte), listagem, denúncia, inscrição e apagamento dos traços do passado, em suma, "literalização imagética" do evento. Sobretudo nos deparamos nesse trabalho com uma materialidade porosa, pesa- 
da - como o asfalto, as pedras, o barro e o chumbo; chumbo aliás, que marca também as obras de um Kiefer e o anti-monumento dos Gerz, e que de certo modo mimetiza o peso do passado e a matéria amorfa e perfurada de nossa memória:

Acho que minha primeira intenção foi construir pequenas "caixas de memória", utilizando o que havia chegado até mim: os nomes dos mortos e seus macabros instantes de publicidade (as notícias de jornal). Pintei com asfalto frio 111 paralelepípedos, ou pequenas lajes, e os recobri com breu. Depositei sobre eles o nome de cada um dos mortos, impressos em chumbo (linotipia), uma notícia de jornal sobre o massacre mergulhada, "mineralizada", em breu e a cinza de 1 salmo, queimando em sua homenagem uma página da bíblia. Escrevi sobre a parede, com letras quase invisíveis de vaselina, um texto meu, anterior ao acontecimento, mas que me parece parente próximo do resto da exposição. As caixinhas sobre a parede, com revestimentos diversos, contêm cinzas de páginas da bíblia e textos de minha autoria impressos no vidro (nem sempre é possível ver isso pelas fotos). As 3 Múmias são feitas de barro cru, de vaselina e cinzas de páginas da bíblia e de vaselina, breu e folhas de ouro. O elemento fino e vertical que parece em algumas das fotos é uma espécie de cruz molenga, feita com a soma dos nomes dos mortos impressos em linotipia. (RAMOS 38).

Acredito que o emprego da mineralização do escrito — tematizada, vale lembrar, na poesia geológica e mnemônica de Paul Celan — concentra nessa obra de Nuno Ramos a poética da arte da memória contemporânea. Nesses minerais que conservam nosso passado decantou-se também uma força explosiva que essas obras tanto guardam quanto detonam. Nosso modesto papel aqui é também ser uma caixa de ressonância desse passado. Entre Simonides de Ceos e Temístocles, tomar nas mãos os fios da arte da memória e do esquecimento: sem a ilusão de consolo, mas também sem ressentimento. Com a certeza apenas que tanto no mito como nas artes da memória antiga e contemporânea, como Goethe e Freud já sabiam, "Im Anfang war die Tat". ("No início foi o ato"; FREUD 1974, 444)

\section{Notas}

\footnotetext{
${ }^{1}$ Este texto foi originalmente escrito para ser apresentado no dia 11 de setembro de 2001, dia dos eventos catastróficos em Nova Iorque e Washington. Ele foi lido no Colóquio Internacional "A Arte da Memória", por nós organizado, que aconteceu no Instituto Goethe de São Paulo entre os dias 11 e 13 do mesmo mês. Diante dos eventos nos EUA, o colóquio - que tratou da memória e história das catástrofes — ganhou uma inusitada e terrível atualidade. O texto é reproduzido aqui tal como ele foi escrito para ser apresentado no colóquio, sendo que nas notas reproduzo de modo aproximativo digressões orais da minha apresentação. Em respeito aos eventos catastróficos, as palestras que deveriam ter sido apresentadas naquele dia 11 foram transferida para o dia 13.

${ }^{2}$ BENJAMIN 1243.

${ }^{3}$ Esse tratado durante muito tempo fora atribuído a Cícero e durante a Idade Média era chamado de "Segunda Retórica de Tullius" (sendo que a "primeira" era considerada como tendo sido o De inventione de Cícero). ${ }^{4} \mathrm{O}$ tratado Ad Herennium distingue entre a memória de coisas, memoria rerum, e memória das palavras, memoria verborum. Ou seja, pode-se tanto estabelecer imagens que representam uma idéia ou condensam algumas idéias, como também estabelecer uma série de imagens correspondendo às palavras de um discurso. Devido à sua dificuldade essa segunda modalidade teve na história da arte da memória um papel secundário.

5 "Para escrever eu necessito de imagens, assim como mostrou-se que para que eu tivesse minhas imagens, preciso de textos. Não posso imaginar um sem o outro.” (GERZ 125)
} 
${ }^{6}$ Nesse sentido é sempre bom recordar a teoria e as obras fotográficas de Moholy-Nagy, sobretudo de seus fotogramas que representam uma suma do dispositivo fotográfico como escritura luminosa: objetos deixados sobre o papel fotográfico eram expostos à luz. A fotografia não é nada mais que a marca do corpo deixada no papel.

${ }^{7}$ Gerz, assim como, de um modo geral, os artistas que lidam com as catástrofes do século XX, sabem que a história não pode ser mais facilmente decantada em "imagens artísticas". Existe a possibilidade de simplesmente mimetizar as "imagens traumáticas", de repetir mecanicamente essas imagens que se fixaram na nossa "memória coletiva". A questão é conseguir sair desse registro da mera repetição (que vemos, por exemplo, na arte dos anos 60 de um Andy Wahrol). A traduzibilidade que antes era pressuposta pela arte da memória clássica, deixa de ser aceita. Cabe ao artista buscar uma solução para dar conta desse passado que não se deixa capturar nas imagens, gêneros e práticas artísticas herdadas. Assim como o literato que se volta para as catástrofes deve buscar o "tom correto" para lidar com esse passado, cada artista busca um dispositivo que abra acesso para o seu "trabalho de memória" (que envolve sempre uma "desmemória”, uma descristalização das criptas). No caso de Gerz, ele costuma encenar a própria mecânica do recalcamento; outros artistas optam pela metáfora fotográfica, outros ainda, pela poética do acúmulo de ruínas traços e documentos do passado, ou mesmo de "restos" dos mortos, sendo que o museu de Auschwitz com suas pilhas de malas, sapatos e cabelos é paradigmático nesse sentido.

${ }^{8}$ Cf. as suas palavras: "Eu não estou do lado dos construtores de monumento e dos fabricantes de ícones. É quase um insulto me dizer que faço monumentos. Eu faço tudo que pode ser feito para que não se faça isso. São dispositivos tudo, menos isso." (MESNARD 89)

${ }^{9}$ Nesse contexto é interessante recordar as várias placas que foram colocadas em Berlim, em pontos particularmente movimentados, com a frase "Orte des Schreckens, die wir niemals vergessen dürfen" "Locais do terror que nós nunca deveríamos esquecer"), seguida da lista dos Campos de Concentração nazistas. A memória é tratada aqui como uma lei: "não esquecereis".

${ }^{10}$ Vale a pena recordar — mas não tenho espaço aqui para me estender sobre essa importante questão — que a fotografia participa da arte da memória com toda uma gama de diferentes elementos desse dispositivo. Antes de mais nada, a fotografia representa o funcionamento do nosso aparato mnemônico enquanto uma placa "fotográfica" onde os traços de memória se inscrevem. Nesse sentido os fotogramas de Maholy-Nagy representam uma espécie de grau zero da arte fotográfica. Marcelo Brodsky explora esse elemento da fotografia: enquanto grafia "lutuosa" do desaparecimento. O princípio da reprodução fotográfica, por outro lado, também é explorado no seu projeto "Buena Memória”: a fotografia reencena aqui o gesto de nossa memória que tenta via repetição das "imagens traumáticas" do passado reverter — tarde demais, après coup — a quebra do nosso mecanismo de defesa contra os choques. Nas suas fotos de espectadores "contemporâneos" refletidos nas fotos com as faces que despontam do passado, vemos a concretização da memória enquanto prática que parte sempre do presente para o passado. Já as fotos do catálogo-album-arquivo "Asservate Exhibits" de Naomi Tereza Salmon trabalham com a manipulação da exposição do objeto fotografado. Ela apresenta de modo super-exposto as peças documentais que ela fotografou em Auschwitz, Buchenwald e Yad Vashem. Pentes, próteses dentárias e pregos enferrujados encontrados nos antigos Campos de Concentração foram fotografados e colocados em um catálogo em forma de arquivo. Quatro fotografias do período nazista encontradas em mercados de antigüidade servem para separar as partes do catálogo correspondentes aos locais onde foram encontrados (ou encontram-se arquivados) os objetos fotografados. A fotografia aqui vai do acento do seu teor documental ao destaque do seu valor estético recordando também, com a técnica da super-exposição, que a luz do real que se subtrai à simbolização queima nossa placa mnemônica e gera uma memória-cicatriz que não se deixa apaziguar e desestabiliza a nossa sempre delicada auto-imagem. O objeto na imagem captada sob o "flash fotográfico da memória traumática" perde os contornos, assim como ocorre nas imagens ofuscadas pelo excesso de luz, pelo sol-negro que cega. Os objetos dilacerados aparecem nas fotos de Salmon isolados, como corpora delicti, fragmentos — recobertos de pátina — de um tempo que resiste tanto às imagens como às palavras.

${ }^{11}$ A arte da memória manteve-se na Idade Média não apenas nas obras de arte com seu fim didático, de, por exemplo, recordar as leis e os pecados, mas também tendeu para a construção de certas figuras de valor alegórico que eram reconhecidas via certos atributos. Esse mesmo procedimento - baseado na electio, na redução exemplar — encontramos na arte renascentista e pós-renascentistas, e se decantou do modo mais explicito na tradição barroca dos emblemas. Cf. YATES. Quanto à relação entre o abjeto e a arte da memória 
devemos recordar que a arte da memória encena aquilo que deixou marcas no nosso corpo - na nossa memória não instrumental, meramente consciente, vinculada ao sistema de proteção dos choques. Daí a arte da memória ter profundas relações com a arte do corpo que também é uma marca das produções atuais. $\mathrm{O}$ redesenhamento do "eu" na dita pós-modernidade passa pela pesquisa do corpo como suporte da memória. Quanto à noção de abjeto na arte moderna cf. SELIGMANN-SILVA 2005.

\section{Bibliografia}

ABRAHAM, N. e TOROK, M., A casca e o núcleo, trad. Maria José Coracini, S. Paulo: Escuta, 1995.

ABRAHAM, N. e TOROK, M., Cryptonymie - Le verbier de l'bomme aux loups, Paris, 1976.

ARISTÓTELES, On the Soul, Parva Naturalia, On Breath, trad. W.S. Hett, Cambridge (Mass.)/ London: Harvard UP, 1957.

ASSMANN, Aleida, Erinnerungsräume. Formen und Wandlungen des kulturellen Gedächtnisses, München: C.H. Beck, 1999.

BENJAMIN, Walter, Fragmentos preparatórios para "Über den Begriff der Geschichte", em Gesammelte Schriften, Frankfurt a.M.: Suhrkamp, vol. I, 1974.

BRODSKY, Marcelo, Buena Memoria. Un ensayo fotográfico de Marcelo Brodsky, Roma, 2000.

ECO, U., “Ars Oblivionalis. Sulla difficoltà di construire un'Ars oblivionalis", in: Kos 30:40-53 (Ingl.: "An ars oblivionalis? Forget it!", in: PMLA 103: 254-261.)

FREUD, S., "Das Unheimlich", in: Freud-Studieausgabe, Frankfurt/M.: Fischer Verlag, 1970, vol IV.

FREUD, S., "Erinnern, Wiederholen und Durcharbeiten", in: Freud-Studieausgabe, Frankfurt/M.: Fischer Verlag, 1975, Ergänzungsband, pp. 205-215.

FREUD, S., "Notiz über den 'Wunderblock"', in: Freud-Studieausgabe, Frankfurt/M.: Fischer Verlag, 1975, vol. III, pp.363-369.

FREUD, S., "Trauer und Melancholie", in: Freud-Studieausgabe, Frankfurt/M.: Fischer Verlag, 1975, vol. III, pp. 193-212.

FREUD, S., “Totem und Tabu”, in: Frend-Studieausgabe, Frankfurt/M.: Fischer Verlag, 1974, vol. IX, pp. 285444.

GERZ, Jochen, Gegenwart der Kunst. Interviews (1970-1995), Regensburg: Lindinger + Schid Verlag, 1995.

GERZ, Jochen, La question secrète. Biron, Arles: Actes du Sud, 1996.

HOHEISEL Horst, e KNITZ, Andreas, Zermablene Geschichte. Kunst als Umweg, Weimar: Thüringisches Hauptstaatsarchiv, 1999

HOHEISEL, Horst, Aschrottbrunnen, Frankfurt/M., Fritz Bauer Institut, 1998.

MESNARD, Philippe, Consciences de la Shoab: Critique des discours et des représentations, Ed. Kimé, 2000.

MÜLLER, Friedhelm L., Kritische Gedanken zur antiken Mnemotechnik und zum Auctor ad Herennium, Stuttgart: Franz Steiner Verlag, 1996.

PLATÃO, Teeto e Crátilo, trad. Carlos Aberto Nunes, Belém: Universidade Federal do Pará, 1988.

RAMOS, Nuno, 111, São Paulo: Gabinete de Arte Raquel Arnaud, 1993.

Rhétorique à Herennius, trad. G. Achard, Paris: Les belles Lettres, 1997.

RICOEUR, Paul, La mémoire, l'histoire, l'oubli, Paris: Seuil, 2000.

SALMON; Naomi Tereza, Asservate. Exbibits. Auschwitz, Buchenwald, Yad Vashem, Frankfurt/M.: Schirn Kunsthalle/ Cantz Verlag, 1995.

SELIGMANN-SILVA, Márcio, "Do delicioso horror sublime ao abjeto e à escritura do corpo", in: M.S-S., O local da diferença. Ensaios sobre memória, arte, literatura e tradução, São Paulo: Editora 34, 2005.

SELIGMANN-SILVA, Márcio e NESTROVSKI, A. (org.), Catástrofe e Representação, São Paulo: Escuta, 2000. WEINRICH, Harald, Lethe. Kunst und Kritik des Vergessens, München: C.H. Beck, 1997.

YATES, Francis A., Art of Memory, University of Chicago Press, 1974.

YOUNG, James, The Texture of Memory: Holocaust Memorials and Meaning, New Haven und London, 1993.

YOUNG, James, At Memory's Edge. After-Images of the Holocaust in Contemporary Art and Architecture, New Haven/London: Yale UP, 2000. 